\title{
Influence of Monomolecular Film Evaporation Retardant on the Plastic Cracking and its Application on Concrete
}

\author{
Wei Wang ${ }^{1, a^{*}}$, Wen Xu ${ }^{1, b}$, Yujiang Wang ${ }^{2, c}$ \\ ${ }^{1}$ State Key Laboratory of High Performance Civil Engineering Materials, Jiangsu Research Institute of \\ Building Science, Nanjing, 210008, China \\ ${ }^{2}$ College of Materials Science and Engineering, Southeast University, Nanjing 211189, China \\ àwangw@cnjsjk.cn, ${ }^{b}$ xuwen@cnjsjk.cn, ${ }^{c} 230159150 @$ seu.edu.cn
}

\section{Keywords: Monomolecular, Water Evaporation, Plastic Cracking, Application}

Abstract. The early age water loss of cement based materials can cause plastic shrinkage cracking and crusting and peeling which will damage the application property and durability of concrete. Through emulsion system of small molecule super amphiphilic compound, stable and compact monomolecular film evaporation retardant on the surface of concrete is being prepared, which will inhibit the water evaporation of plastic concrete and then restrain plastic shrinkage cracking. In a harsh evaporation environment, the inhibition ratio of evaporation retardant was tested, which displays $24.1 \%$ and $59.6 \%$ inhibition ratio separately when sprayed once and twice while water nearly makes no difference to the evaporation rate. Surface appearance of cement paste and concrete applied evaporation retardant shows no crusting and peeling phenomenon. Evaporation retardant can inhibit the plastic shrinkage cracking of concrete and will reduce the total cracking area per unit area more than an order of magnitude. Evaporation retardant has been successfully applied in many key projects in China where the evaporation is high and makes a great contribution to the durability of concrete structures.

\section{Introduction}

With the application of high performance concrete, the plastic shrinkage cracking due to water evaporation has become a common and remarkable problem when casting under hot, dry and windy conditions. Plastic shrinkage cracking occurs when the rate of water loss on the surface exceed the rate of bleeding internally. Because of the application of the superplasticizer and grinding mineral admixtures, the bleeding water of high performance concrete is significantly reduced and the larger fluidity makes the evaporation much higher, thus leads to serious plastic shrinkage cracking [1-6]. The cracking would lower the durability and shorten the service life of the concrete for the increased permeability of the harmful deleterious substances.

Traditional curing methods usually starts after the initial setting which are not suitable for high performance concrete. Covering plastic film on the surface of plastic stage concrete will change the surface appearance and is not proper when in a windy environment. The most effective and direct method to prevent the plastic shrinkage cracking is to restrain the water loss of the concrete [7-10]. Similar to the retention of water in soil and reservoir, the evaporation retardant of plastic concrete has been invented and is used more and more widely $[11,12]$.

In this paper, a monomolecular film evaporation retardant is applied to study its influence on the early age plastic shrinkage cracking and its application on concrete structures are been introduced briefly. The evaporation retardant is prepared through emulsion system of small molecule super amphiphilic compound and which realize the self-assembly on the surface of plastic concrete and then the stable and compact monomolecular film will inhibit the water evaporation of plastic concrete and plastic shrinkage cracking development and improve the finishing property notably. 


\section{Experimental}

Raw materials. Reference Cement conforming to the Standard GB 8076-2008 Concrete Admixture in cement paste and P•II 52.5 Portland cement conforming to the Standard GB 175-2007 Common Portland Cement in concrete were used in this study. A natural river sand and crushed limestone (continuous grading size of 5 to $20 \mathrm{~mm}$ ) were used as fine and coarse aggregate. The evaporation retardant used in this study was Ereducer-101 High Effective Evaporation Retardant and the superplasticizer used in this study was High Performance Polycarboxylic Acid Superplasticizer which are all produced by Jiangsu Sobute New Materials Co., Ltd. The chemical composition of cementitious materials is presented in Table 1.

Table 1. Chemical composition[\%]of cementitious materials

\begin{tabular}{cccccccc}
\hline Cementitious Materials & $\mathrm{SiO}_{2}$ & $\mathrm{Al}_{2} \mathrm{O}_{3}$ & $\mathrm{CaO}$ & $\mathrm{MgO}$ & $\mathrm{Fe}_{2} \mathrm{O}_{3}$ & $\mathrm{SO}_{3}$ & Loss \\
\hline Reference Cement & 20.6 & 4.6 & 62.6 & 2.6 & 3.2 & 3.0 & 2.0 \\
P•II 52.5 Cement & 18.2 & 4.2 & 68.1 & 1.6 & 3.9 & 1.9 & 1.11 \\
Fly ash & 47.5 & 31.6 & 7.3 & 1.2 & 5.6 & 1.0 & 0.8 \\
\hline
\end{tabular}

\section{Mix proportions.}

Cement paste. The testing benchmark of water evaporation is cement paste. In this study, a 0.4 water cement ratio was applied.

Concrete. For the research of plastic shrinkage cracking, two kinds of strength grade concrete were prepared as shown in Table 2.

Table 2. Concrete mixture proportions $\left[\mathrm{kg} / \mathrm{m}^{3}\right]$

\begin{tabular}{ccccccc}
\hline Strength Grade & Cement & Fly ash & Water & Sand & Stone & Superplasticizer \\
\hline C30 & 330 & 0 & 200 & 710 & 1160 & 0 \\
C50 & 379 & 3.122 & 156 & 682 & 1161 & 3.122 \\
\hline
\end{tabular}

\section{Testing methods}

Water evaporation. The water evaporation of the cement paste or concrete was tested according to Chinese Industrial Standard JG/T 477-2015 Evaporation retardant for concrete during plastic stage which was characterized by weighing $4 \mathrm{~h}$ later after casting under such environmental condition: temperature $=(38 \pm 2)^{\circ} \mathrm{C}$, humidity $=(32 \pm 3) \%$, and the wind speed $=(5 \pm 1) \mathrm{m} / \mathrm{s}$. The evaporation retardant was sprayed on the cement paste surface within $10 \mathrm{~min}$ after cement paste or concrete was cast.

Plastic shrinkage cracking. Plastic shrinkage cracking of concrete was tested according to Test Method for Early Cracking of Concrete of Chinese standard GB/T 50082-2009 Standard for test methods of long-term performance and durability of ordinary concrete. The test condition was $(20 \pm 2)^{\circ} \mathrm{C}$ and $(60 \pm 5) \%$ $\mathrm{RH}$ with a wind speed of $(5 \pm 0.5) \mathrm{m} / \mathrm{s}$.

\section{Results and discussion}

Inhibition ratio of water evaporation. Inhibition ratio of water evaporation is a significant performance index for evaporation retardant. According to Chinese Industrial Standard JG/T 477-2015 Evaporation retardant for concrete during plastic stage, cement paste with a 0.4 water/cement ratio was prepared to test the inhibition ratio of water evaporation in the harsh evaporation environment as described in section 2.3. Evaporation retardant and pure water were separately sprayed on the surface of tested cement paste once and twice. Evaporation retardant and pure water were applied as soon as finishing and 30min later when 
sprayed twice. The dosage of evaporation retardant and pure water sprayed on the surface every time in this study were $250 \mathrm{~g} / \mathrm{m}^{2}$. The results are shown in Table 3. The inhibition ratio of water evaporation was calculated as Eq. (1).

Table 3. Water evaporation of cement paste

\begin{tabular}{cccc}
\hline \multirow{2}{*}{ Sample } & \multicolumn{2}{c}{ Average rate of water evaporation $\left[\mathrm{kg} / \mathrm{m}^{2} / \mathrm{h}\right]$} & $\begin{array}{c}\text { Inhibition ratio of water evaporation } \\
{[4 \mathrm{~h}, \%]}\end{array}$ \\
\cline { 2 - 3 } & $2 \mathrm{~h}$ & $4 \mathrm{~h}$ & $/$ \\
\hline Reference & 1.46 & 1.41 & 8.5 \\
Water(1) & 1.33 & 1.29 & 8.5 \\
Water(2) & 1.20 & 1.29 & 24.1 \\
Ereducer(1) & 1.06 & 1.07 & 59.6 \\
Ereducer(2) & 0.52 & 0.57 & \\
\hline
\end{tabular}

${ }^{a}$ The number in standard brackets indicate the time of application of evaporation retardant or water.

$\mathrm{Q}=\left(1-\frac{\bar{G}_{c}}{\bar{G}_{0}}\right) \times 100$

with

Q Inhibition ratio of evaporation retardant [\%]

$\bar{G}_{0} \quad$ Average rate of water evaporation of reference samples $[\mathrm{g}]$

$\bar{G}_{c}$ Average rate of water evaporation of tested samples [g]

It can be seen that Ereducer evaporation retardant can reduce the evaporation by $24.1 \%$ and $59.6 \%$ seperately when sprayed once and twice, while water cannot reduce evaporation which indicate that spraying water on the plastic cement based material will provide no early age curing.

Surface appearance. Serious crusting and peeling will occur when the water evaporation is rapid and intense. Cement paste and concrete were investigated in the harsh evaporation environment as described in section 2.3 and the surface appearance was observed $4 \mathrm{~h}$ later after casting.

It can be seen that the cement paste without evaporation retardant presented serious crusting, peeling and plastic shrinkage cracking phenomenon in Fig. 1. Spraying water on the surface of cement paste cannot restrain plastci cracking. Evaporation retardant will greatly reduce this harmful effect when placed in hot, dry and windy environment. 


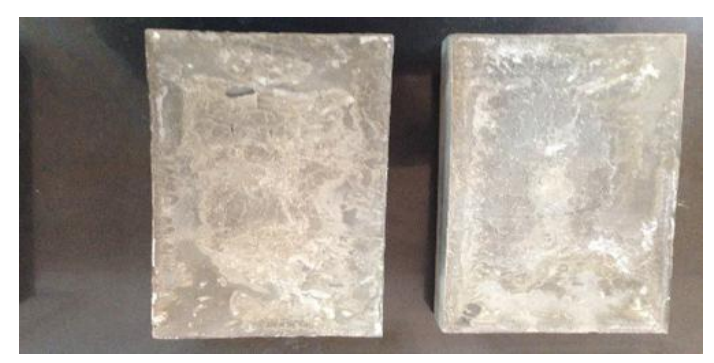

(a) Reference sample-crusting and peeling

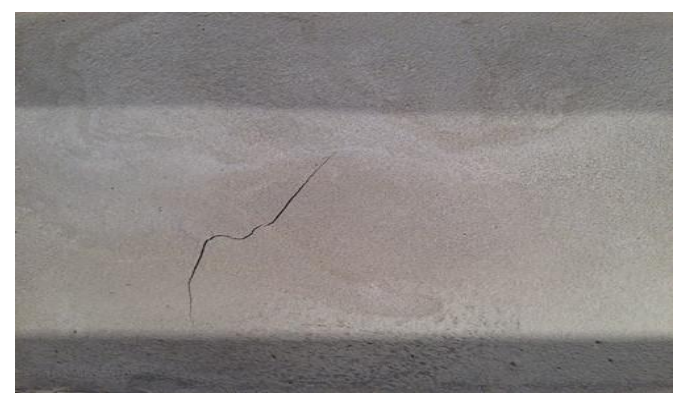

(c) Water sample-whiting and plastic cracking

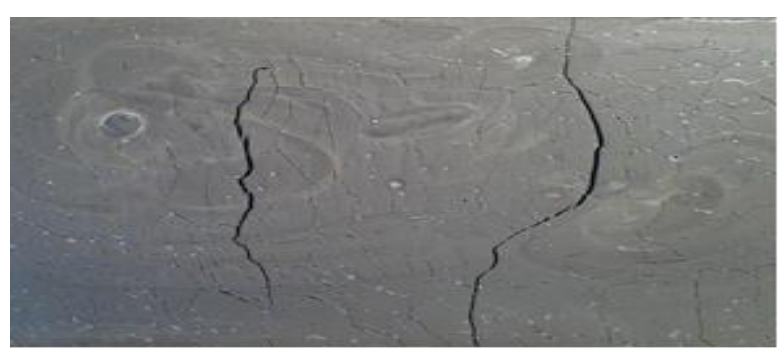

(b) Reference sample-plastic cracking

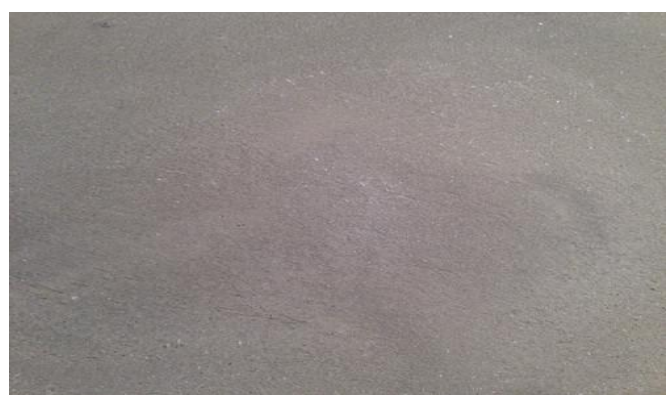

(d) Ereducer evaporation retardant sample

Fig. 1. Surface appearance of cement paste after $4 \mathrm{~h}$ water evaporation test

In this study, the surface appearance of C30 concrete was also tested. Pure water and evaporation retardant were separately sprayed in the surface of concrete as soon as casted.

4h later, the surface of concrete presented different features as shown in Fig. 2. There was serious crusting, peeling and unsuitable hardening on the surface of reference sample. For the concrete sprayed pure water, the surface became white and aggregates exposed apparently. Likewise, evaporation retardant will improve the surface appearance dramatically which presented smoothly. It is important to note that the cement paste and concrete were all without finishing operation.

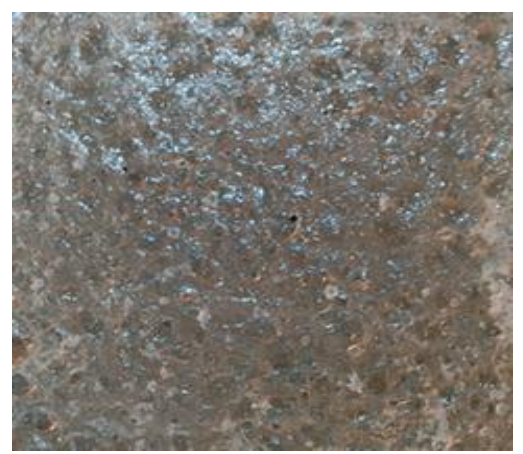

(a) Reference sample

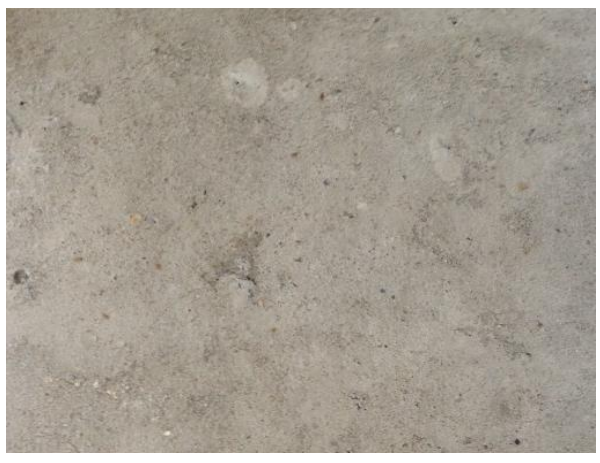

(b) Ereducer sample

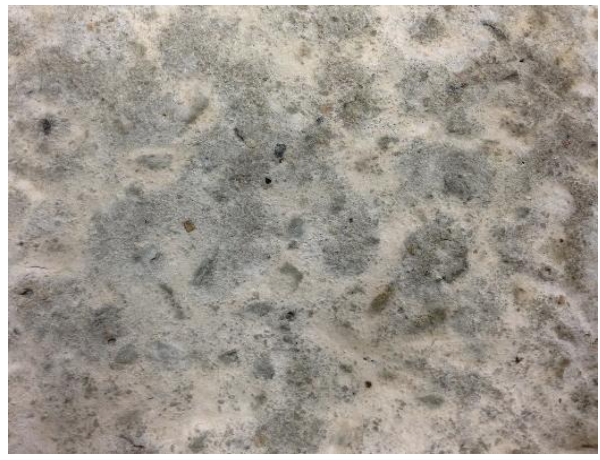

(c) Water sample

Fig. 2. Surface appearance of $\mathrm{C} 30$ concrete after $4 \mathrm{~h}$ water evaporation test 
Plastic shrinkage cracking. Plastic shrinkage cracking test was applied in C30 and C50 concrete separately. After placing in the specified condition $24 \mathrm{~h}$ later, observing the crack development.

For $\mathrm{C} 30$ concrete, because of a high water cement ratio, there were only 2 cracks, one of which was 1.10 mm width. However, there were no cracks for concrete sprayed evaporation retardant. Spraying water can reduce the total cracking area per uint area from $550 \mathrm{~mm}^{2} / \mathrm{m}^{2}$ to $76 \mathrm{~mm}^{2} / \mathrm{m}^{2}$, but the number of cracks per unit area is larger. Thus, evaporation retardant can effectively reduce plastic shrinkage cracking.

Table 4. Statis tical date of plastic cracks of C30 concrete

\begin{tabular}{cccc}
\hline Sample & Number of cracks & Length of crack[mm] & Maximum width of crack[mm] \\
\hline Reference & 2 & (1) $402 、(2) 208$ & (1) $1.10 、(2) 0.40$ \\
Water & 3 & (1) $320 、$ (2) $180 、(3) 155$ & (1) $0.10 、(2) 0.15 、(3) 0.10$ \\
Ereducer & None & $/$ & $/$ \\
\hline
\end{tabular}

Table 5. Cracking parameters of tested samples of C30 concrete

\begin{tabular}{ccc}
\hline Sample & Number of cracks per unit area $\left[\mathrm{crack} / \mathrm{m}^{2}\right]$ & Total cracking area per uint $\left.\operatorname{area}^{2} \mathrm{~mm}^{2} / \mathrm{m}^{2}\right]$ \\
\hline Reference & 4.2 & 550 \\
Water & 6.3 & 76 \\
Ereducer & 0 & 0 \\
\hline
\end{tabular}

Table 6. Statis tical date of plastic cracks of C50 concrete

\begin{tabular}{|c|c|c|c|}
\hline Sample & Number of cracks & Length of crack[mm] & Maximum width of crack $[\mathrm{mm}]$ \\
\hline Reference & 5 & $\begin{array}{l}\text { (1) } 600 、(2) 160 、(3) 180 、 \\
\text { (4) } 260 、 \text { (5) } 180\end{array}$ & $\begin{array}{l}\text { (1) } 0.50 、 \text { (2) } 0.25 、(3) 0.10 、 \\
\text { (4) } 0.15 、 \text { (5) } 0.10\end{array}$ \\
\hline Water & 2 & (1)600、(2)600 & (1) $0.55 、$ (2) 0.40 \\
\hline Ereducer & 1 & (1) 490 & (1) 0.10 \\
\hline
\end{tabular}

Table 7. Cracking parameters of tested samples of C50 concrete

\begin{tabular}{ccc}
\hline Sample & Number of cracks per unit area $\left[\mathrm{crack} / \mathrm{m}^{2}\right]$ & Total cracking area per uint ${\operatorname{area~}\left[\mathrm{mm}^{2} / \mathrm{m}^{2}\right]}^{\text {Reference }}$ \\
Ereducer & 10.4 & 437 \\
Water & 2.1 & 53 \\
\hline
\end{tabular}

As high strength and high performance concrete used more and more widely, the water cement ratio become lower. Meanwhile, superplasticizer and mineral admixture increased in concrete. The $\mathrm{C} 30$ concrete cannot reflect modern concrete characters. Therefore, C50 concrete was also been tested. There were 5 cracks on the surface of Reference concrete and only 1 crack of Ereducer concrete sample. As to the total cracking area per unit area, the Reference concrete and Water concrete are $437 \mathrm{~mm}^{2} / \mathrm{m}^{2}$ and $601 \mathrm{~mm}^{2} / \mathrm{m}^{2}$ separately while the Ereducer spraying concrete is only $53 \mathrm{~mm}^{2} / \mathrm{m}^{2}$, which meant evaporation retardant can reduce the total cracking area per unit area of more than one order of magnitude and water will not inhibit plastic cracking. At the same time, Ereducer evaporation retardant will lower the number of cracks per unit area about $80 \%$. 


\section{Application}

Ereducer evaporation retardant has been successfully applied on many key projects in China especially in the northwest of China. For example, the Lanzhou-Urumchi High-speed Railway and Baoji-Lanzhou High-speed Railway, they are all in dry and windy environment.

Lanzhou-Urumchi High-speed Railway pass through a harsh evaporation environment area where endure hot, dry and windy condition thus leads to high evaporation. Monitoring data of environment in September indicates that the atmospheric temperature is beyond 30 Celsius degree and the surface temperature of concrete will reach 42 Celsius degree under direct sunshine while the relative humidity is less than 30 percent and the wind speed exceeds $9 \mathrm{~m} / \mathrm{s}$. In addition, this area belongs to the Temperate continental droughty desert climate and it's very expensive to curing the fresh concrete by spraying water.

There were serious plastic cracking and crusting phenomenon before finishing of track slab while no curing method was applied timely, which also hindered the finishing process. After spraying Ereducer evaporation retardant as soon as casted, the crusting and peeling phenomenon were alleviated and the plastic shrinkage cracking was reduced dramatically while the finishing process can be conducted smoothly. This technique was used all fronts of Lanzhou-Urumchi High-speed Railway.
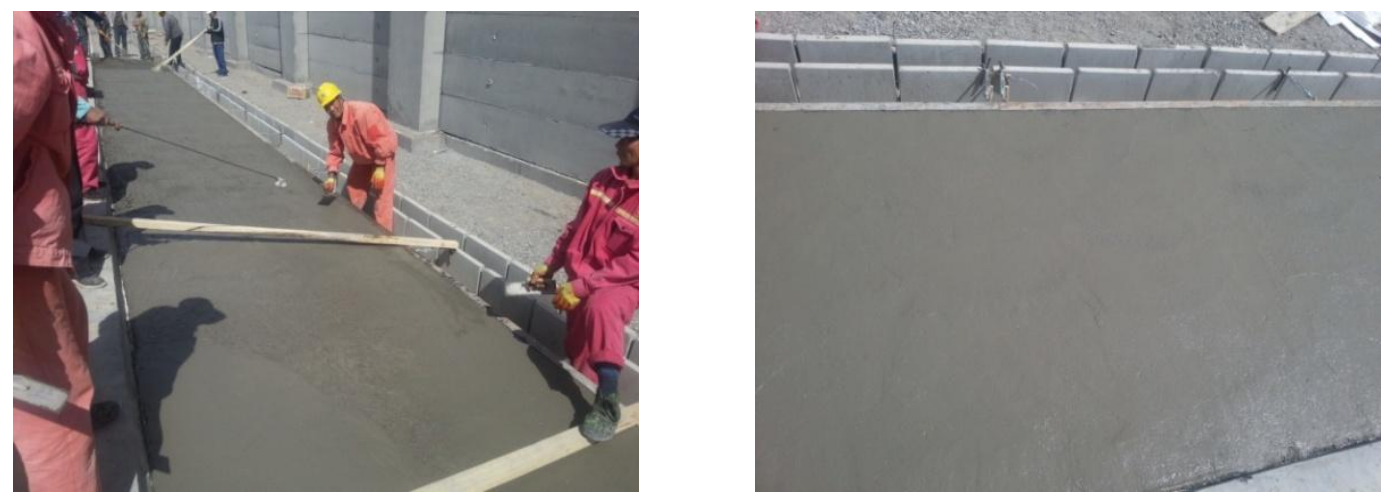

Fig.3. Application of evaporation retardant on the track slab of High-speed railway

\section{Conclusions}

Evaporation retardant, as an early age curing material which is applied as soon as the concrete is casted, can inhibit water evaporation effectively. This new curing material for cement based materials is applied more and more popular especially in the hot, dry and windy environment where the plastic shrinkage cracking is severe.

The effect of evaporation retardant on the early age plastic shrinkage cracking and surface appearance were investigated in this paper and the application was briefly introduced. The following conclusions were drawn:

1) Evaporation retardant can reduce water evaporation of cement paste of 0.4 water cement ratio of $24.1 \%$ and $59.6 \%$ separately when applied once and twice in $38^{\circ} \mathrm{C}$ and $32 \% \mathrm{RH}$ environment, with a wind speed of $5 \mathrm{~m} / \mathrm{s}$.

2) Evaporation retardant can relieve the peeling and crusting phenomenon of concrete greatly and make the surface appearance smooth.

3) Evaporation retardant can inhibit the plastic shrinkage cracking of concrete and will reduce the total cracking area per unit area more than an order of magnitude.

4) Evaporation retardant has been successfully applied in many key projects in China where the water evaporation of concrete is high. 


\section{Acknowledgements}

This work has been supported by the Technological Development Program of China Railway (No. 2014G001-C), the Provincial Science and Technology Cooperation Project of Jiangsu Province Jiangsu-Guangxi cooperation project (BM2014050) and the Science and Technology Plan Project of Jiangsu Province Communications (2015T30). The authors gratefully acknowledge to the colleagues in program team, thanks very much for their hard work. The authors also acknowledge to the help of cooperate from some construction companies.

\section{References}

[1] D.P. Bentz, A review of early properties of cement-based materials, Cement and Concrete Research. 38(2008)196-204.

[2] J. Justsa, M. Wyrzykowskia, D. Bajareb, P. Luraa, Internal curing by superabsorbent polymers in ultra-high performance concrete, Cement and Concrete Research. 76(2015) 82-90.

[3] Doo-Yeol Yooa, Kyung-Hwan Minb, Joo-Ha Leec, Young-Soo Yoona, Shrinkage and cracking of restrained ultra-high-performance fiber-reinforced concrete slabs at early age, Construction and Building Materials. 73(2014) 357-365.

[4] Miao Chang-wen, Tian Qian, Sun Wei, Liu Jia-ping, Water consumption of the early-age paste and the determination of "time-zero" of self-desiccation shrinkage, Cement and Concrete Research. 37(2007)1496-1501.

[5] Andreas Leemann, Peter Nygaard, Pietro Lura, Impact of admixtures on the plastic shrinkage cracking of self-compacting concrete, Cement and Concrete Composites. 46(2014)1-7.

[6] Hui Chen, Mateusz Wyrzykowski, Karen Scrivenera, Pietro Lurab, Prediction of self-desiccation in low water-to-cement ratio pastes based on pore structure evolution, Cement and Concrete Research. 49(2013)38-47.

[7] M. Ibrahim, M. Shameem, M. Al-Mehthel, M. Maslehuddin, Effect of curing methods on strength and durability of concrete under hot weather conditions, Cement and Concrete Composites. 41(2013)60-69.

[8] Wang Yiran, Zhang Zhiqing, Li Juan, Yu Lei, Experimental Study on Preventive Measures of Plastic Shrinkage Cracking of Cement Concrete, Procedia - Social and Behavioral Sciences. 96(2015)196-204.

[9] W.J McCartera, A.M Ben-Saleh, Influence of practical curing methods on evaporation of water from freshly placed concrete in hot climates, Building and Environment. 36(2001)919-924.

[10] S. Machida, S. Mineta, A. Fujimori, H. Nakahara, Retardation of water evaporation by less-defective mixed monolayers spread from bulk solids onto water surface, Journal of Colloid and Interface Science. 260(2003)135-141.

[11] GT. Barnes, The potential for monolayers to reduce the evaporation of water from large water storages, Agricultural Water Management. 95(2008)339-353.

[12] J.P. Liu, L. Li, C.W. Miao, Q. Tian, Q.P. Ran, Y.J. Wang, Characterization of the monolayers prepared from emulsions and its effect on retardation of water evaporation on the plastic concrete surface, Colloids Surf. A. 36(2010) 208-212. 